\title{
O novo sentido do trabalho para o sujeito pós- moderno: uma abordagem crítica
}

\author{
El nuevo sentido del trabajo para el sujeto posmoderno: un abordaje crítico
}

The new meaning of labour for the post-modern subject: a critical approach

\author{
Ricardo Henry Dias Rohm ${ }^{1}$ \\ Universidade Federal do Rio de Janeiro / Faculdade de Administração e Ciências Contábeis, Rio de Janeiro - RJ, Brasil \\ Natália Fonseca Lopes ${ }^{2}$ \\ Universidade Federal do Rio de Janeiro / Faculdade de Administração e Ciências Contábeis, Rio de Janeiro - RJ, Brasil
}

\begin{abstract}
Resumo
Análise sobre as maneiras como a sociedade gerencial desenvolve nas mentes uma representação do mundo e da própria pessoa humana, de modo que o único caminho aparente de realização de si consista na lógica da produtividade e em sua relação psíquica e social, tornando a empresa uma referência para a construção do sujeito. Hoje, há necessidade de um eu maleável, sempre aberto a novas experiências; são essas as condições adequadas ao trabalho de curto prazo, a instituições flexíveis e à nova empregabilidade. Esta última constitui um macrodispositivo de controle micropolítico na produção de subjetividades. Richard Sennett afirma que o sentido da vida e da morte não se contabiliza. $\mathrm{E}$ é por isso que se deve dar vazão às relações humanas e à satisfação da alma, e não só ao capital, ao capitalismo. Para embasar este artigo, busca-se o caminho de construção da noção de trabalho até alcançar o gerenciamento atual na pós-modernidade. Espera-se, assim, ampliar a compreensão desse fenômeno e viabilizar a produção de métodos mais eficazes e humanizantes da prática de gestão de pessoas nas organizações. Será adotada a pesquisa bibliográfica por meio da revisão de literatura em Ciências Sociais e da Teoria Crítica aplicada à análise da administração na atualidade. A Teoria Crítica busca desenvolver articulações que penetrem a forma e substância, visando questionar a realidade aparente e abarcar a realidade encoberta nas estruturas organizacionais.
\end{abstract}

Palavras-chave: Subjetividade. Trabalho. Vínculos humanos. Teoria crítica.

\section{Resumen}

Análisis acerca de las maneras en que la sociedad de gerencia desarrolla en las mentes una representación del mundo y de la propia persona humana, por lo que el único camino aparente de autorrealización consista en la lógica de la productividad y en su relación psíquica y social, convirtiendo a la empresa en una referencia para la construcción del sujeto. Hoy, hay necesidad de un yo maleable, siempre abierto a nuevas experiencias; son estas las condiciones adecuadas para el trabajo a corto plazo, para instituciones flexibles y para los nuevos puestos de trabajo. Esta última

Artigo submetido em 28 de fevereiro de 2014 e aceito para publicação em 10 de junho de 2014

\section{DOI: http://dx.doi.org/10.1590/1679-395117179}

${ }^{1}$ Doutor em Administração pela Fundação Getulio Vargas/EBAPE; Professor da Faculdade de Administração e Ciências Contábeis da Universidade Federal do Rio de Janeiro (FACC/UFRJ); Fundador e coordenador do Programa de Estudos e Pesquisas em Desenvolvimento Humano, Formação de Lideranças e Governança Corporativa (PEP-ROHM). Website do Programa: http://peprohm.wix.com/peprohm. Endereço: Av. Pasteur, 250, Praia Vermelha, CEP 22290-902, Rio de Janeiro - RJ, Brasil. E-mail: ricardorohm@terra.com.br

${ }^{2}$ Graduada em Administração pela Faculdade de Administração e Ciências Contábeis da Universidade Federal do Rio de Janeiro (FACC/UFRJ); Integrante do Programa de Estudos e Pesquisas em Desenvolvimento Humano, Formação de Lideranças e Governança Corporativa (PEP-ROHM). Endereço: Av. Pasteur, 250, Praia Vermelha, CEP 22290-902, Rio de Janeiro - RJ, Brasil. Email: lopes.natalia@yahoo.com.br 
constituye un macro-dispositivo de control micro-político en la producción de subjetividades. Richard Sennett afirma que el sentido de la vida y la muerte no se contabilizan. $Y$ es por eso que uno debe dejar paso a las relaciones humanas y a la satisfacción del alma, y no sólo al capital, al capitalismo. Para apoyar este artículo, se busca el camino de construcción de la noción de trabajo hasta llegar a la gestión actual en la posmodernidad. Se espera, así, ampliar la comprensión de este fenómeno y hacer viable la producción de métodos más eficaces y humanizadores de la práctica de gestión de personas en las organizaciones. Se adoptará búsqueda bibliográfica a través de la revisión de literatura en Ciencias Sociales y de la Teoría Crítica aplicada al análisis de la administración en la actualidad. La Teoría Crítica busca desarrollar articulaciones que penetren en la forma y la sustancia, con el fin de cuestionar la realidad aparente y abarcar la realidad oculta en las estructuras organizativas.

Palabras clave: Subjetividad. Trabajo. Vínculos humanos. Teoría crítica.

\section{Abstract}

The objective of this article is to examine the ways in which the management society develops a representation of the world and the human being in their minds, so that the only apparent way of self-realization consists of the logic of productivity and its psychical and social relations, making the companies a reference for human development. Today there is a need of a self-malleable being, always open to new experiences; these are appropriated conditions for a short term job: flexible institutions and the new employment conditions. Employability is a macro-device of micro-political control in the production of subjectivities (ROHM, 2003). Sennett (2000) says that the meaning of life and death does not count. And that is why you should open up to human bonds and soul satisfaction, and not only to capitalism. To support this article, we seek the constructive path of the concept of work to achieve the current management in post-modernity. Thus it is expected to broaden the understanding of this phenomenon and enable the production of more effective methods and humanizing practice of managing people in organizations. A bibliographic research will be adopted through reviewing the literature of social sciences and critical theory applied to the analysis of the current management. According to Faria (2007), Critical Theory aims to develop formulations that penetrate the shape and substance, seeking to question the apparent reality and embrace the reality hidden in organizational structures.

Keywords: Subjectivity. Labor. Human Bonds. Critical Theory.

\section{Introdução}

O trabalho é uma condição fundamental na existência humana. Por meio dele, o Homem se relaciona com a natureza, constrói sua realidade, significa-se, insere-se em contextos grupais, atua em papéis e finalmente promove a perenização de sua existência. Por viabilizar a relação dos indivíduos com o meio, em um dado contexto, o trabalho expressa-se como incessante fonte de construção de subjetividade, produzindo significado da existência e do sentido de vida. Todavia, o trabalho na pós-modernidade ocupa de tal forma um espaço no desejo do indivíduo que as pessoas buscam somente neste papel o sentido de suas vidas, inviabilizando a autorrealização plena do ser humano.

Neste artigo são analisadas as maneiras como a sociedade gerencial desenvolve nas mentes uma representação do mundo e da própria pessoa humana, de modo que o único caminho aparente de realização de si consista na lógica da produtividade e em sua relação psíquica e social, tornando a empresa uma referência para a construção do sujeito.

Será adotada a pesquisa bibliográfica por meio da revisão da literatura em ciências sociais e na teoria crítica aplicada à análise da administração na atualidade. Espera-se que este artigo seja útil à Administração em geral, e ao campo dos estudos organizacionais em particular. Busca-se ainda ampliar a compreensão da nova subjetividade e os vínculos humanos na sociedade gerencial, viabilizando a produção de métodos mais eficazes e humanizantes da prática de gestão de pessoas nas organizações.

Este artigo está divido em sete partes. Após esta introdução, apresenta-se um breve histórico do caminho de construção da noção de trabalho em nossa sociedade, destacam-se as principais mudanças de conjuntura 
política, econômica e social no mundo e que trouxeram novas concepções e práticas ao processo de trabalho. Será dada uma ênfase maior ao sistema de produção capitalista, nosso modelo atual.

Na sequência, aponta-se como a mudança cada vez mais frequente no mundo, por conta da imposição do sistema capitalista, exige uma adaptação constante das organizações. No decorrer, expõe-se a Teoria Crítica, principal abordagem utilizada neste artigo, para uma análise das organizações, uma vez que tal teoria tem como objetivo ir à raiz dos problemas. Para a Teoria Crítica, não basta compreender a forma sem o conteúdo e a aparência sem a essência (FARIA, 2007).

Em seguida, serão abordadas as questões mais relevantes ligadas ao trabalho na pós-modernidade, suas contradições nas concepções sobre o trabalho flexível e os impactos na vida do trabalhador na atualidade. Com base nessas constatações, sugere-se o valor universal de solidariedade e respeito às pessoas e à natureza como forma de recuperação do sentido de viver e da existência humana.

\section{A Evolução do Trabalho}

No início das civilizações o trabalho tinha como objetivo a sobrevivência, restringindo-se à coleta de plantas ofertadas pela natureza e à caça de animais, atividades predominantemente físicas. Ao homem competia a caça e à mulher, as atividades que não necessitavam de muito esforço físico. Disso decorria uma divisão biológica do trabalho, sem necessidade de grandes escolhas, pois se buscavam os recursos naturais disponíveis.

Na Idade Média surge o feudalismo, caracterizado pela estratificação das camadas sociais e do trabalho em si. Nesse sistema cabia aos nobres, proprietários das terras, a atividade de segurança, e aos camponeses, o trabalho na terra para sustento próprio e do feudo, sem preocupação com a troca de mercadorias entre as comunidades. Nessa época, a Igreja Católica detinha bastante poder e o trabalho, por influência do Antigo Testamento, era visto como uma punição.

Próximo ao término da Idade Média, com a Reforma Protestante, outra conotação surge para o trabalho, este passa a ser considerado como algo virtuoso, capaz de levar o homem à salvação. Nesse período, o artesão era dono dos seus instrumentos de trabalho e dominava seu ofício, podia perceber, assim, o produto acabado de seu trabalho.

Com a Revolução Industrial, processo iniciado em fins do século XVIII e que implicou uma mudança radical na cultura material do Ocidente, ocorre uma gradativa substituição da utilização da força manual pela força das máquinas, o que configurou a transição do feudalismo para uma nova forma de organizar e pensar a produção: o sistema capitalista.

Com o aparecimento da burguesia e o surgimento do capitalismo, o trabalhador começa a ficar sem a propriedade dos seus meio de produção e, aos poucos, sua sobrevivência torna-se dependente da venda de sua "força de trabalho". Citando Marx, Duarte (2004) afirma que:

[...] o operário vende sua força de trabalho, ou seja, que a força de trabalho do operário é, na sociedade capitalista, uma mercadoria. Mas essa forma de trabalho é uma forma historicamente situada, que surgiu juntamente com os demais aspectos essenciais que caracterizam a sociedade capitalista, que é a sociedade que sucedeu ao feudalismo e que existe até hoje. (DUARTE, 2004, p. 48).

Segundo Motta (2003), a Teoria da Administração, seja empresarial, pública, da educação ou de qualquer outro tipo, teve origem com a Revolução Industrial por meio da absorção da produtividade como finalidade do trabalho. O desenvolvimento das máquinas muda a relação do homem com a natureza e leva à paulatina desintegração da sociedade europeia, cuja ascendência social era pouco comum. Duplica em um século a 
população daquele continente, multiplicam-se as cidades industriais, e a produção domiciliar e manufatureira dão lugar à produção fabril. É um período de grande mobilidade e de grandes deslocamentos sociais. A burguesia dá um salto em sua trajetória ascendente, e grandes massas populacionais dirigem-se para os centros industriais, onde a extrema miséria convive com a riqueza. Para Vianna (2005), o sistema adotado pela revolução fez surgir uma nova forma de escravidão, com o crescimento daqueles que detinham a fortuna e a servidão dos menos abastados.

Segundo Faria (1996), a Abordagem Clássica da Administração tinha o propósito de resolver os problemas decorrentes do crescimento acelerado e desorganizado das empresas, que precisavam encontrar formas eficientes de racionalizar o trabalho e aumentar a produção. Essa abordagem teórica reuniu as ideias de Taylor e Fayol, que ficaram conhecidos como os precursores das Escolas Científica e Clássica da Administração. A divisão técnica do trabalho surgiu fortemente no século XX, momento em que o capitalista procurava escolher o trabalhador que melhor se adaptasse ao posto de trabalho. Nesse período, o taylorismo e o fordismo propuseram a produção em massa por meio de uma racionalização baseada no incremento do ritmo de trabalho como forma de aumento da exploração do trabalhador (ANTUNES, 1998).

Na teoria taylorista observa-se que, "[...] além do estudo das tarefas, da seleção do trabalhador mais adequado para a sua execução e do treinamento, configuram-se, entre os objetivos tayloristas de racionalização do trabalho, os incentivos salariais com vistas à elevação da produtividade" (MERLO e LAPIS, 2007, p. 63), sendo esse modelo de gerenciamento empresarial prejudicial à saúde do trabalhador. O autor afirma, também, que esse tipo de trabalho, no qual não se permite autonomia ao trabalhador, deixa marcas que aparecem em outros ambientes (não laborais), acompanhadas de queixas de sofrimento físico e psíquico.

Quando o fordismo passou a predominar no sistema produtivo, trouxe a divisão do trabalho da ótica da hierarquização e da pré-determinação de funções, inibindo a autonomia e a criatividade do trabalhador. O processo produtivo passou a ser fragmentado, o trabalhador deixou de ter a sensação de elaborar sozinho o produto, como acontecia anteriormente na fase do trabalhador artesão. Assim, o trabalhador exercia a sua atividade em uma unidade fabril em troca de um salário medido com base na produtividade que o capitalista almejava. As mudanças no mercado de trabalho, com o acúmulo de trabalhadores desempregados ou subempregados, permitem que o capitalista regule sua demanda de mão-de-obra dentro de uma lógica produtiva que "[...] vem convertendo a concorrência e a busca da produtividade num processo destrutivo que tem gerado uma imensa precarização do trabalho e aumento monumental do exército industrial de reserva, do número de desempregados" (ANTUNES, 1999, p. 16).

As inovações tecnológicas postas pela microeletrônica e, consequentemente, as novas técnicas de produção provocaram a falência da ideologia fordista, abrindo as portas para um novo modelo, o toyotista, com ênfase nos processos de "qualidade total". O toyotismo, modelo japonês, aparece na década de 70 e provoca profundas modificações no processo de trabalho, as quais trouxeram uma maior exploração e controle sobre a força de trabalho, bem como uma maior flexibilização do trabalho por meio da redução dos direitos sociais e trabalhistas (ABRAMIDES e CABRAL, 2003).

A cada incorporação de novos modelos do sistema produtivo, exigia-se do trabalhador mais esforço e aprendizagem contínua para adaptação face às novas posturas e competências exigidas. As mudanças provocadas no mundo e nas relações do trabalho afetam a maneira de ser do trabalhador, e contribuem para o desemprego, diferença salarial, informalidade, desvalorização da força de trabalho, atingindo também órgãos representativos da classe trabalhadora. A década de 1980 marcou o momento mais crítico na história do mundo do trabalho com uma dupla crise: uma que atingiu a materialidade, a objetividade da classe trabalhadora, e a outra como resultante da primeira que alcançou o plano da subjetividade do trabalho (ANTUNES, 1998).

O emprego não é sinônimo de trabalho, é uma condição posta ao trabalho remunerado e reconhecida socialmente. Trabalhar significa aprender a fazer e saber fazer alguma coisa que transforma a realidade e a própria pessoa que trabalha. Portanto o trabalho não pode ser considerado uma tortura para o ser humano e, 
sim, um processo de desenvolvimento e valorização do homem sobre a natureza. Do mais simples ao mais complexo trabalho, pelo corpo humano (mãos, braços, voz, olhos, ouvidos, cérebro...) criamos o mundo à nossa volta e participamos, conscientes ou não, de um movimento social que tanto conserva e regenera quanto muda a realidade.

À luz dos postulados de Marx, compreende-se que o processo de trabalho que ultrapassa a alienação e se concretiza pelo conhecimento e práxis permite a subsistência do trabalhador, desde a sua simples alimentação até ao progresso da humanidade. O consenso de um processo de trabalho sadio, no qual o ser social tenha a liberdade para criar e ser criado, transformar e ser transformado, satisfaz o trabalhador, contribuindo para a evolução cultural, social, econômica e tecnológica do próprio ser e do mundo.

No entanto, as mudanças de conjuntura política, econômica e social no mundo trouxeram para o âmbito do trabalho novas concepções e práticas ao processo de trabalho, ao trabalhador e às relações sociais. Com a explosão do capitalismo no mundo, o processo educativo e de desenvolvimento do ser social por meio do trabalho é negligenciado. Os conhecimentos não são transmitidos com a sua verdadeira significância social, o trabalho e a educação passam a ser compreendidos como simples obrigação do homem, para melhoria do nível de renda, promoção social e inserção na sociedade capitalista.

O capitalismo tem como prioridade a acumulação do capital. Assim, compreende-se que na medida em que se expande o sistema capitalista, o trabalho deixa de ser um artesanato, um prolongamento das ações do homem, uma extensão dos seus braços, uma projeção de sua vontade, uma expansão de sua criatividade. $\mathrm{O}$ homem não participa dos destinos do seu trabalho, quase sempre nem vê o produto final, não se sente criador da obra.

A lógica do mercado capitalista gera muitas contradições entre o capital e trabalho, uma vez que o nível de exploração produz a ameaça constante do conflito e o temor da própria elite. Como enfrentamento das tensões produzidas, as elites capitalistas elaboraram novas formas de disciplina social, aumentando o controle sobre o trabalho na produção e nas relações sociais. Objetivando economizar tempo e eliminar ao extremo os gestos e atitudes improdutivas, criaram vários métodos de controle de produção, extinguindo a possibilidade do ócio criativo diante do processo de trabalho humano mecânico.

É importante desvelar que a sociedade global emergente é resultado de um movimento de caráter estrutural do capitalismo, que, com forte teor ideológico, adquire poder determinante de conformação, sobretudo de novos padrões sociais. Embora se observem inúmeras mudanças no que se refere ao trabalho, ainda hoje se estabelece a mesma dinâmica do passado. Por um lado, o trabalho dissociado do seu sentido não passa de uma atividade em que o trabalhador perde-se a si mesmo, negando sua própria vida. Por outro, o trabalho não perdeu sua importância uma vez que se trata do meio de sobrevivência do homem.

\section{A Gestão Contemporânea}

Atualmente, o processo de mudanças no interior das organizações é impulsionado pelas mudanças constantes das informações e pelo surgimento de novas tecnologias em diversas áreas. Nessa perspectiva, as organizações podem se considerar atualizadas somente por breves momentos, uma vez que em curto espaço de tempo o saber e as informações estarão defasados pelas constantes mudanças sociais, econômicas e tecnológicas (MOTTA, 1993).

Diversos estudos sobre tendências na gestão de organizações demonstram que práticas gerenciais tradicionais tais como as burocráticas não atendem mais às necessidades de melhor desempenho das organizações. Embora sejam ainda muito frequentes, acabam por dificultar o gerenciamento já que não conseguem alcançar a complexidade crescente das atividades coletivas e mudanças ambientais. Hoje têm predominado a incerteza e a instabilidade em detrimento de valores perseguidos como a centralização e a previsibilidade, que não atendem mais às expectativas do mercado. 
De acordo com Motta (1993) e Drucker (1997), as organizações que ainda refletem os modelos da Escola Clássica de Administração terão de implantar um processo de mudança organizacional mais dinâmico e descentralizado. Os tradicionais modelos de administração estão sendo trocados por uma administração inovadora, com estruturas cada vez mais enxutas e ágeis. De acordo com Motta (1993), a descentralização das decisões é uma característica fundamental da administração flexível.

Atualmente, percebemos as organizações como entes contraditórios, nas quais convivem estruturas formais e subjetivas, manifestas e ocultas, concretas e imaginárias (FARIA, 2007; 2009).

Segundo Faria (2007), os estudos nas áreas organizacionais incorporaram nos últimos anos outras disciplinas, como Psicologia, Antropologia, Economia, que agregaram um olhar mais amplo e trouxeram novas reflexões à prática da administração nas organizações.

Desse modo, a fim de contribuir para uma análise crítica dos vínculos gerenciais e para a nova subjetividade do trabalhador emergente na pós-modernidade, faz-se necessário buscar uma proposta multidisciplinar que traga outras visões, além daquelas das teorias gerais da administração. Os estudos sobre as organizações devem aprofundar as análises sobre o uso do poder e suas formas de controle, dispensando ensaios rasos sobre as políticas e racionalidades instrumentais.

A Teoria Crítica, nos estudos organizacionais, preconiza que é necessário compreender as questões que afetam a vida cotidiana dos sujeitos e valorizar o sujeito coletivo mais do que as organizações em que trabalham (FARIA, 2007; 2009).

Cabe destacar que, dentro da proposta multidisciplinar da Teoria Crítica, a formação e a influência dos autores provêm de áreas diversas, ou seja, para construir uma produção crítica é necessária uma condição multidisciplinar, pois, embora a atenção deste artigo esteja voltada para o tema da administração, outros olhares são necessários para polemizar.

\section{A Teoria Crítica}

De acordo com Faria (2004), a Teoria Crítica surgiu na Escola de Frankfurt, criada por marxistas conhecidos hoje como a parte do marxismo ocidental. Os pesquisadores visam a análise marxista direcionada para emancipação em detrimento da tirania e opressão.

A Teoria Crítica pretende denunciar a repressão e o controle social a partir da constatação de que uma sociedade sem exploração é a única alternativa para que se estabeleçam os fundamentos da justiça, da liberdade e da democracia. (FARIA, 2004, p. 25).

Sendo assim, qualquer tipo de totalitarismo, autoritarismo e coerção são fortemente abominados. A Teoria Crítica centra-se na emancipação, na liberdade e no esclarecimento (FARIA, 2004; MOZZATO e GRZYBOVSKI, 2013). Possui fundamentos marxistas, mas de certo marxismo; tem fundamentos no sujeito visando ao coletivismo. Seus teóricos foram os primeiros a fazer a ligação do pensamento da psicanálise com o marxismo para tentar inserir o sujeito na análise, uma vez que o marxismo, até então, não dava conta dessa relação. A Teoria Crítica, respaldada por fundamentações teóricas, busca questionar e transformar a realidade a fim de entender os sujeitos e suas relações sociais.

Para realizar pesquisas em Teoria Crítica, ocorreu a necessidade de rejeitar certas noções de positivismo, racionalismo e objetivismo, olhar para a verdade histórica e social totalmente integradas, pois a Teoria Crítica surgiu em um momento social e histórico muito particular. As mudanças nos processos produtivos, principalmente tecnológicas, no final do século XX, proporcionaram uma alteração nos rumos das organizações. Questões anteriormente ignoradas a favor da produção começaram a ser questionadas. 
Conforme já mencionado, é na Revolução Industrial, quando acontece a ruptura de uma forma de trabalho artesanal para dar lugar a produção de bens e serviços por meio de máquinas, caracterizando uma divisão estrutural da sociedade entre capital e trabalho cuja finalidade é a produtividade e a geração de lucro. $\mathrm{O}$ avanço tecnológico propiciou a transferência da riqueza acumulada no campo para as fábricas e centros urbanos por meio da aquisição de tecnologia - daí decorre a separação entre a força de trabalho e os instrumentos que permitem produzir bens. É o nascimento do capitalismo como uma construção histórica.

Desse modo, o mercado aparece como instituição neutra, no qual trocas justas são realizadas. Embora se afirme a predominância da liberdade e igualdade no mercado, o fato é que as trocas entre indivíduos e organizações não são iguais, pois ambos possuem recursos em escalas e medidas diferentes. Além disso, a liberdade e a igualdade não são conceitos aplicáveis quando a lógica é a da competição.

As ciências se submetem cada vez mais à lógica do capital, tornam-se forças produtivas deste, ou seja, o conhecimento tende a ser comercializado pelos interesses do capital (HABERMAS, 1982) e a ciência a tornar-se ela própria ideologia (HABERMAS, 1997). Os avanços científicos, que deveriam atender a todos, passam a atender a poucos, mais especificamente àqueles que podem pagar pelo acesso aos novos conhecimentos (TRAGTENBERG, 1982; GORZ, 2005). É a produção do conhecimento a serviço do sistema capitalista.

Por isso, a Teoria Crítica visa à emancipação dos indivíduos e à conscientização crescente da necessidade de uma sociedade em que os interesses coletivos prevaleçam sobre os individuais. Faz-se necessário questionar se as ações sociais não são métodos paliativos e indagar sobre os atos dos sujeitos que têm como objetivo atender a interesses de grupos específicos na estruturação do poder. Isto, portanto, é condição essencial para construir uma sociedade detentora da sua própria história, consciente das suas responsabilidades e das suas atribuições coletivas (FARIA, 2007).

Do ponto de vista das organizações produtivas sob o comando do capital, é importante analisar questões que não são pacíficas, penetrar em seu mundo obscuro para entender, por exemplo, o fato de que para intensificar o trabalho, incrementando a exploração e submetendo os empregados ao constante estresse e adoecimento de natureza psicossomática (GAULEJAC, 2007), a organização passa a adotar programas gerenciais anestésicos, aplicados em doses cada vez mais eficazes. Na seção a seguir, aborda-se essa necessidade de conhecer melhor as técnicas de gestão contemporâneas, as novas políticas de administração de pessoas, as novas tecnologias de controle psicossocial e político, as armadilhas da linguagem ("nossos colaboradores"; "nossos associados"), os programas de aprisionamento e sedução; enfim, tudo o que transmite duplas mensagens no discurso e na prática organizacional (FARIA, 2007).

\section{O Trabalho na Pós-Modernidade}

As concepções sobre o trabalho na pós-modernidade começaram a se alterar entre os dirigentes organizacionais, seguidores de teóricos considerados gurus da administração de empresa, tais como Naisbitt (1994) e Toffler (1987). Devido ao acirramento da concorrência, as empresas foram pressionadas a passar por mudanças profundas. Os empresários que mantivessem uma visão estrita dos seus negócios assumiriam o risco de serem eliminados pela concorrência, não apenas vinda do exterior, mas de outros setores de atividades em seu país.

No início da pós-modernidade, o trabalho começou a sofrer alterações devido à adoção de concepções com relação à flexibilização do capital e dos processos de trabalho por parte dos detentores do poder econômico nas sociedades ocidentais. A flexibilização foi aceita como propícia às reestruturações necessárias à manutenção do capitalismo, de acordo com Harvey (1996), por ocorrer em prol da sustentação do capital, ou seja, por manter as mesmas premissas com vistas à lucratividade. 
Quando o processo de trabalho deixou de ter uma base taylorista-fordista para ser substituído pelo toyotismo, marcado pela produção flexível e enxuta, passou a se requerer um novo tipo de trabalhador. Não seria mais suficiente um trabalhador que vencesse a separação entre as atividades mentais e manuais do período taylorista. Exige-se um trabalhador que integre pensamento e ação, e que também possa criar, produzir conhecimentos úteis para a organização capitalista. Esse processo não se constitui mais de operários que executam tarefas repetitivas, mas de trabalhadores do conhecimento, cuja função é agregar outro tipo de valor aos produtos ou aos processos de produção e gestão. Entre as principais características exigidas para esse trabalhador, podemos destacar: uma postura flexível, subordinável, ágil, aberta a mudança em curto prazo e boa adaptabilidade para conviver com um ambiente de incertezas (FERRER, 1998). Ao determinar esse perfil, há o interesse da empresa em atender os objetivos estratégicos e influenciar na internalização dessas características como se fossem dos próprios sujeitos (ANTUNES, 1999).

De acordo com Baztán (2002), cada empresa conta com uma cultura formada por um conjunto de crenças, princípios e informações que devem ser internalizados pelos sujeitos. Por meio da internalização dos valores organizacionais, os trabalhadores são impelidos a atingir os resultados empresariais.

Na modernidade, a ordem, a eficiência, a organização do trabalho e a hierarquia verticalizada eram valores organizacionais que deviam ser internalizados pelos indivíduos. Já na pós-modernidade, o caos rege as principais práticas organizacionais. $\mathrm{O}$ foco do trabalho passou a ser a sua eficácia e os seus resultados; os meios utilizados para atingi-los não têm importância. Por se tratar de valores elásticos, que mudam a depender dos interesses empresariais, tornam-se de difícil internalização (ANTUNES, 1999).

Bauman (1999) alerta para a contradição presente no modelo de trabalho flexível, uma vez que, por um lado, o novo perfil profissional exigido - subordinável, ágil e adaptável - demanda profissionais que não possuam um alto grau de envolvimento afetivo na sua relação com o trabalho. Por outro lado, para que os trabalhadores internalizem os objetivos organizacionais, é necessário que se dediquem intensamente e despendam uma forte carga emocional nele. Em decorrência disso, os sujeitos são suscetíveis de serem avaliados como incompetentes caso falhem nas entregas e resultados, permanecendo sob o risco da demissão (DEJOURS, 2000).

A lógica da descentralização e autonomia também é mais um fator que pesa sobre o risco de demissão dos trabalhadores, pois embora possam escolher os meios para atingir suas metas e resultados, deparam-se com desafios de difícil realização, o que se agrava pelo número reduzido de integrantes na equipe. Para que as tarefas fossem cumpridas, houve uma tendência de que os sujeitos mantivessem uma jornada de trabalho com um ritmo incessante e com muitas horas-extras, com prejuízo ao alcance sistemático das metas e dos resultados (SENNETT, 2000).

De acordo com estudos realizados, o nível de estresse no ambiente de trabalho está relacionado com a pressão sofrida pelos trabalhadores e a falta de controle e delegação que estes possuem em suas atividades, potencializando o risco à saúde psíquica do sujeito (CHIRKOV, RYAN e CHELSEA, 2005). A ameaça de demissão, portanto, é um risco sempre presente, disseminando o medo no ambiente empresarial. $\mathrm{O}$ medo pode imobilizar o indivíduo uma vez que este deixa de analisar adequadamente o contexto ao seu redor para discernir e melhor compreender a realidade.

Além disso, o perfil profissional do trabalho flexível exige que os trabalhadores sejam capazes de se relacionar com facilidade e tenham boa adaptabilidade aos diferentes ambientes. Desse modo, são capazes de trabalhar em equipe, porém o ambiente social do trabalho nem sempre é favorável para a convivência entre os sujeitos, pois, embora no discurso organizacional prevaleça a valorização do trabalho em equipe, na prática, o ambiente é hostil e competitivo (DEJOURS, 2000). A convivência conflituosa torna-se, desse modo, mais uma causa para o risco de demissão.

As novas formas de regulação do trabalho, mediante "contratos temporários", "horário flexível", "trabalho part-time", "redução de jornada", "teletrabalho" e outras, são práticas que visam agregar valor somente à 
empresa; o trabalhador fica à deriva na medida em que perde a capacidade de mobilização coletiva, tornando-se solitário.

Além disso, devido à grande oferta de trabalhadores desempregados, o medo foi instaurado no ambiente empresarial - há a ameaça constante da substituição fácil de um sujeito por outro (DEJOURS, 2000). Profissionais com perfil inadequado e desempenho aquém do esperado sofrem risco de demissão, e podem ser trocados por profissionais do mercado cuja remuneração seja até mesmo inferior.

De acordo com Giddens (2000), na pós-modernidade surge o risco fabricado. Aquele que o próprio sujeito cria para si mesmo na esfera das crenças e suposições. O risco fabricado implica autorresponsabilização do sujeito por seu sucesso-fracasso e emprego-desemprego. Há a cobrança contínua e tormentosa que o trabalhador se impõe para se enquadrar às exigências dos empregadores (ROHM, 2003).

Conforme se abordou, é necessário investigar, nos estudos organizacionais, as formas de controle social e as maneiras como o poder é exercido pelas empresas. As organizações investem em formas sofisticadas de controle, principalmente em relação à subjetividade dos trabalhadores, que passam a reproduzir os jargões empresariais, assumindo a incumbência de atingir os resultados e a acumulação de capital no local onde trabalham. Os sujeitos se tornam incapazes de compreender exatamente como tal processo de dominação acontece, tamanha a sutileza e acuidade da manipulação exercida.

É importante analisar as razões pelas quais os sujeitos não reagem às formas de controle e dominação dos dirigentes empresariais. De acordo com Faria (2007), há o medo de perder o emprego e, consequentemente, das dificuldades financeiras daí decorrentes. No âmbito das necessidades do ser humano quanto a aceitação e inserção no meio social, há o receio de ser excluído do grupo ao qual pertence. Outra razão para a ausência de reação estaria na dificuldade de o indivíduo reconhecer o sofrimento do qual é vítima, pois assumir isto agravaria sua dor, faria-o questionar o sentido do seu trabalho e admitir as incoerências que permeiam este mundo do poder.

Conforme Enriquez (1997), as organizações visam controlar para alcançar seus resultados de produção. Por meio deste controle, impõem medos e dispositivos de vigilância que inibem os sujeitos a buscar a emancipação. "É por reconhecer a existência e a importância da subjetividade que as organizações investem no controle psicossocial" (FARIA, 2004, p. 124). É preciso, portanto, desbravar os estratagemas do mundo empresarial e identificar os discursos e práticas organizacionais para além do que pode ser percebido à primeira vista.

Os sujeitos desenvolvem um vínculo emocional com as organizações onde trabalham, pois é inerente ao ser humano maximizar o prazer no seu estar no mundo (ROHM, 2003). Para além do retorno monetário, os indivíduos esperam ser reconhecidos e delegam às empresas a responsabilidade pelo seu sucesso pessoal, transferindo para elas seu ideal de realização. Já as organizações não desenvolvem nenhum tipo de relação emocional com o empregado além do estritamente estabelecido no contrato de trabalho; a relação é de caráter utilitário. Dessa maneira, as conquistas da organização passam a ser seus ganhos. Esta identificação com a organização pressupõe que o indivíduo entregue-se à sua empresa de corpo e alma, resultando na criação de uma realidade ilusória (FARIA, 2004). A aceitação dos ideais da organização por parte do sujeito é tão fortemente interiorizada que, quando este é dispensado pela organização, tal ato é sempre justificado em nome de um objetivo maior.

Existem diversos mecanismos de controle no ambiente empresarial, entre os quais podemos citar o modelo ideal do fundador da empresa, que deve ser cultuado por todos os empregados como referência para a construção do sujeito. Outro exemplo é o do funcionário modelo, o que possui um desempenho e comportamento exemplares e que mais se alinha com os padrões estabelecidos pela empresa. Estes são modelos que devem ser copiados para que os demais empregados se identifiquem com a organização. Existem ainda comitês de avaliação do desempenho ou grupos de averiguação do padrão de qualidade, que pretendem garantir a ordem no ambiente de trabalho em alinhamento com as diretrizes empresariais. 
Outro aspecto de controle que precisamos levar em consideração diz respeito à apreensão da subjetividade do trabalhador. Como o sujeito não consegue realizar seu ideal do ego, projeta seu ideal no ideal da empresa. Desse modo, o sucesso da empresa é adotado pelo sujeito como seu próprio sucesso também. O sujeito envolve-se e dedica-se cada vez mais para possuir o reconhecimento e ser admirado pelo seu trabalho. Busca no alcance dos resultados empresariais o sentido e o propósito da sua vida.

Assim, o sujeito desenvolve uma relação de dependência, pois não consegue mais viver sem esse vínculo com a empresa onde trabalha. O sujeito é um moderno escravo da empresa e de si mesmo. Às vezes, um escravo contente, porque é inconsciente desses mecanismos de controle exercido sobre ele. Há um sentimento de pertença. O sujeito, portanto, se sente parte da "família organizacional", veste a camisa.

Observa-se que sempre há dilemas éticos para enfrentar. E se a isso não é dada a devida atenção, tornamonos cúmplices pela indiferença. O homem não deve ser o estereótipo do homo economicus, que se preocupa apenas com o lucro, mas, sim, buscar esse lucro de forma ética, prezando também pelas relações humanas.

\section{Por uma Gestão mais Humana}

De acordo com Vieira e Vieira (2004), a base da Teoria Crítica está, pois, no seguinte postulado: “[...] é impossível mostrar as coisas como realmente são, senão a partir da perspectiva de como elas deveriam ser". $\mathrm{Na}$ verdade, o "dever ser" refere-se às possibilidades não realizadas pelo mundo social. Não tem caráter utópico, mas analisa o que o mundo poderia ter de melhor se suas potencialidades se realizassem. A identificação das potencialidades permite entender mais claramente como o mundo funciona e, dessa forma, identificar os obstáculos à realização das suas capacidades latentes. Assim, a Teoria Crítica aponta para a prática por meio da realização desses potenciais, por meio da identificação e rompimento dos obstáculos. Diante do que já foi exposto, tais potenciais são de natureza necessariamente emancipatória.

Segundo Gaulejac (2007), a economia não pode ser pensada independentemente da sociedade. O oiko nomos significa, em grego, a "organização da casa". Essa "eco-nomia" deveria respeitar os princípios fundamentais do desenvolvimento sustentável - garantindo a renovação dos recursos e proteção do meio ambiente -, visar ao desenvolvimento social por meio do bem-estar coletivo e, como último princípio, considerar a vida psíquica de cada indivíduo, garantindo a satisfação das necessidades individuais e coletivas. Desse modo, o propósito da economia deixa de ser o incentivo ao consumo, elevação do nível social unicamente por meio de aquisições materiais e do desenvolvimento do capitalismo para priorizar condições de vida mais harmoniosas.

Esses princípios visam à empresa como uma construção antropológica em ruptura com os paradigmas apresentados neste artigo sobre a gestão pós-moderna. Nessa forma de gestão, a ciência e a pesquisa são postas mais a serviço do bem comum e da demanda social do que a critérios de utilidade e lucratividade.

Assim, a compreensão de gestão não deve ser realizada por meio de modelos teóricos inspirados nas ciências exatas, como o positivismo e o utilitarismo, e, sim, nas ciências sociais, já que a finalidade da empresa não é exclusivamente econômica e financeira, mas, em primeiro lugar, humana e social. O trabalho, portanto, não pode ser considerado unicamente sob o ângulo da produção e dos resultados, mas igualmente sob o ângulo do sentido da atividade, da subjetividade e da vivência, que são variáveis tão importantes quanto a produção e a rentabilidade.

Dessa forma, a gestão recuperará a credibilidade que perdeu se puder trazer mais sentido e menos insignificância, mais compreensão e menos prescrição, mais análise qualitativa e menos medida quantitativa. Trata-se, assim, de uma gestão mais humana, que recuse instrumentalizar os homens, considerando-os como um custo ou como um recurso. 
Segundo Gaulejac (2007), cada indivíduo é produtor da sociedade e das organizações nas quais vive dizemos em geral "às quais ele pertence". Ser sujeito é não pertencer a ninguém, nem a pessoas físicas nem a pessoas morais. O sujeito pertence apenas a si mesmo. Entretanto, ele sabe que não se pode ser sujeito sem se confrontar com a alteridade, sem se inserir em um coletivo, sem contribuir com o bem comum. A própria essência da colaboração e da criatividade humana encontra sua fonte em formas de organização que permitem a cada um de seus membros desenvolver suas potencialidades próprias, respeitando, ao mesmo tempo, os outros. A gestão deveria, portanto, preocupar-se com aquilo que "faz sociedade". A empresa não encontra sua finalidade em si mesma. Ela é um meio, entre outros, para produzir a sociedade e melhorar o bem-estar coletivo, até daqueles que não lhe "pertencem". Ela deve, portanto, levar em conta as consequências de seu funcionamento, tanto humanas quanto sociais e do meio ambiente, integrando esses diferentes parâmetros em seu sistema de gestão.

Os homens não podem trabalhar e viver sem dar sentido a suas ações. Quando a atividade faz sentido para o sujeito, sua adesão está adquirida. Ele pode então mobilizar todas as suas capacidades reflexivas e criativas. Não há nenhuma necessidade de grandes discursos quando há uma coerência entre os objetivos perseguidos e os meios postos em prática. Espera-se da gestão essa coerência - que cruelmente faz falta nas empresas gerencialistas - entre o vivido e o conceito, entre o prescrito e o realizável, entre a cifra e o que ela mede. A discussão coletiva, o confronto dos pontos de vista permitem dar novamente sentido à ação, avaliar sua pertinência, pôr novamente regulação em um mundo ameaçado pelo caos. No caso de participação efetiva, o trabalhador teria real acesso ao seu lugar de sujeito, e o trabalho poderia ter, para ele, não um sentido de alienação, mas de realização.

A possibilidade de introdução de novas formas de atuar em Gestão de Pessoas requer, pois, maiores investigações, uma vez que esse terreno é dominado por teorias e práticas funcionalistas, visando prevalentemente aos interesses do capital. É inegável, no entanto, especialmente nos meios acadêmicos, que existe uma corrente crítica dos discursos e das práticas organizacionais. Porém, quando examinamos a maioria das publicações relativas à Administração, percebemos nelas a falta de embasamento teórico ou, mais que isso, de um modelo de pensamento crítico frente aos modismos gerenciais que sempre se repetem sob rótulos diferentes, o que impede os profissionais de Gestão de Pessoas de buscar novas alternativas à sua atuação. Logo, as práticas tradicionais, bem como as oriundas da reestruturação produtiva, estão a serviço do pensamento dominante no sistema gestionário, fundado essencialmente na racionalidade instrumental - já que a racionalidade instrumental é norteada por eficácia, rendimento e desempenho (FERNANDES e PONCHIROLLI, 2011). Por sua vez, nossa proposta de Gestão de Pessoas mais humana deve ser guiada pela racionalidade substantiva, fundamentada nas obrigações éticas e morais (FERNANDES e PONCHIROLLI, 2011).

Este exercício de análise crítica da ambiguidade do trabalho na pós-modernidade abre a possibilidade de visualizar práticas que restituam ao coletivo de trabalhadores seu lugar de sujeito na organização. Espera-se viabilizar a produção de métodos mais eficazes e humanizantes da prática de gestão de pessoas nas organizações, desde que o termo "humanização" não se reduza a vazias armadilhas retóricas, perversamente presentes em inúmeros receituários de administração de recursos humanos. Ainda restam brechas para intervir nas organizações e instituições na perspectiva aberta pela corrente crítica da administração.

\section{Conclusão}

Pode-se perceber que o trabalho precisa dar significado e sentido ao trabalhador e objetivar a coletividade e subjetividade, numa tentativa de superar o gerencialismo corroído pela voracidade do capitalismo e consumo exacerbado, atualmente instaurados (GAULEJAC, 2007). O intuito do gerenciamento atual está no pragmatismo dos objetivos dos trabalhadores para que estes se adéquem aos interesses econômicos das empresas e acionistas. Na sociedade gerencial, o indivíduo deve estar preparado para mudar de emprego, de lugar, de modo de vida, sob o risco de, não aceitando as condições impostas, ficar fora do emprego ou 
estigmatizado como retrógado. A identidade de profissão é substituída pela identidade flexível, polivalente, que varia de acordo com a imprevisibilidade da carreira.

A competição é instaurada como nova norma; assim, o trabalhador é convencido de que o propósito existencial dos homens no mundo, e, portanto, seu papel, se efetiva apenas pela realização de si por meio de luta de posições e espaços em uma corrida incessante por produtividade (ROHM, 2003). O resultado, conforme exposto, seria uma nova sociedade global paradoxal, em que se antagonizam cada vez mais riqueza e pobreza, conhecimento e ignorância, bem-estar e sofrimento, proteção e insegurança.

A implicação dessa proliferação de nova gestão de mundo, eficaz e perverso, que invadiu todo o tecido social, é um mundo de sofrimento, doente socialmente, a impor ao trabalhador uma pressão contínua que o leva a inúmeras formas de doença e sofrimento no trabalho. $\mathrm{O}$ mundo do trabalho, dessa forma, caminha cada vez mais para o sofrimento cruel e individualista dos trabalhadores.

Conforme se viu, o novo poder de controle que surge do desenvolvimento da relação gerencialista é difícil de ser contestado, pois os conflitos se colocam no nível psicológico em termos de insegurança, de sofrimento psíquico, depressões nervosas, esgotamento profissional com perturbações psicossomáticas como a síndrome do burnout (GAULEJAC, 2007; DEMEROUTI, BAKKER e LEITER, 2014). É de difícil contestação porque opera na interioridade do indivíduo, o que faria com que ele se contestasse a si próprio.

Desse modo, a Teoria Crítica pode ser muito útil à Administração em geral e ao campo dos estudos organizacionais em particular. É um dos caminhos possíveis na busca da emancipação do homem, na direção de uma sociedade melhor e mais justa (FARIA, 2007; MOZZATO e GRZYBOVSKI, 2013). Na academia, ela ajuda a construir um tipo de conhecimento e a realizar um tipo de ciência mais apropriado às nossas raízes históricas e culturais.

Neste artigo, pôde-se ver como o capitalismo flexível é devastador. Tão nocivo que consegue destruir, nas pessoas, valores como união, compreensão e sabedoria, para a supremacia do individualismo, cuja ética renega valores que não signifiquem facilitar a acumulação do dinheiro de maneira compulsiva. Corrompe, assim, o caráter do indivíduo, os laços que o tornam realmente forte, como os relacionados à família, às instituições, aos relacionamentos de amizade e solidariedade - a essência boa que deve permear nossas vidas.

Espera-se que este trabalho possa despertar em leitores do meio empresarial um olhar diferente e crítico para a gestão no interior das organizações, no sentido de: visar às organizações como microssociedades, cujo funcionamento remeta tanto à gestão como à antropologia; considerar o homem como um sujeito, mais que um recurso; analisar a empresa como uma instituição social e não um organismo com finalidade estritamente econômica e construir uma economia mais solidária e preocupada com os laços sociais. 


\section{Referências}

ABRAMIDES, M. B. C.; CABRAL, M. S. R. Regime de acumulação flexível e saúde do trabalhador. Revista São Paulo em Perspectiva, v. 17, n. 1, p. 3-10, 2003.

ANTUNES, R. Adeus ao trabalho? Ensaios sobre as metamorfoses e a centralidade do mundo do trabalho. 5. ed. São Paulo: Cortez, 1998.

ANTUNES, R. Os sentidos do trabalho: ensaio sobre a afirmação e a negação do trabalho. São Paulo: Boitempo, 1999.

BAUMAN, Z. Modernidade e ambivalência. Rio de Janeiro: Zahar, 1999.

BAZTÁn, S. A. G. La cultura de la empresa. Revista Mal-Estar e Subjetividade, v. 2, n. 2, p. 86-122, 2002.

CHIRKOV, V. I.; RYAN, R. M.; CHELSEA, W. Cultural context and psychological needs in Canada and Brazil: testing a selfdetermination approach to the internalization of cultural practices, identity, and well-being. Journal of Cross-Cultural Psychology, v. 36, n. 4, p. 423-443, 2005.

DEJOURS, C. A banalização da injustiça social. 3. ed. Rio de Janeiro: Fundação Getulio Vargas, 2000.

DEMEROUTI, E. A. B.; BAKKER, A. B.; LEITER, M. Burnout and work engagement: the JD-R approach. Journal of Occupational Health Psychology, v. 19, n. 1, p. 96-107, 2014.

DRUCKER, P. As novas realidades. São Paulo: Pioneira/Thomson Learning, 1997.

DUARTE, N. Formação do indivíduo, consciência e alienação: o ser humano na psicologia de A. N. Leontiev. Caderno CEDES, v. 24, n. 62, p. 44-63, 2004.

ENRIQUEZ, E. A organização em análise. Petrópolis: Vozes, 1997.

FARIA, J. C. Administração: introdução ao estudo. 2. ed. São Paulo: Pioneira, 1996.

FARIA, J. H. Economia política do poder: fundamentos. Curitiba: Juruá, 2004.

FARIA, J. H. Economia política do poder: as práticas do controle nas organizações. Curitiba: Juruá, 2004.

FARIA, J. H. (Org.). Análise crítica das teorias e práticas organizacionais. 1. ed. São Paulo: Atlas, 2007.

FARIA, J. H. Teoria crítica em estudos organizacionais no Brasil: o estado da arte. Cadernos EBAPE.BR, v. 7, n. 3, p. 509-515, 2009.

FERNANDES, V.; PONCHIROLLI, O. Contribuições da racionalidade comunicativa, racionalidade substantiva e ambiental para os estudos organizacionais. Cadernos EBAPE.BR, v. 9, n. Edição Especial, p. 604-626, 2011.

FERRER, F. Reestruturação capitalista: caminhos e descaminhos da tecnologia da informação. São Paulo: Moderna, 1998.

GAULEJAC, V. Gestão como doença social: ideologia, poder gerencialista e fragmentação social. São Paulo: Idéias e letras, 2007.

GIDDENS, A. Mundo em descontrole. Rio de Janeiro: Record, 2000.

GORZ, A. O imaterial: conhecimento, valor e capital. São Paulo: Annablume, 2005.

HABERMAS, J. Conhecimento e interesse. Rio de Janeiro: Zahar, 1982.

HABERMAS, J. Técnica e ciência como “ideologia”. Lisboa: Edições 70, 1997. 
HARVEY, D. Condição pós-moderna: uma pesquisa sobre as origens da mudança cultural. 6. ed. São Paulo: Edições Loyola, 1996.

MERLO, A. R. C.; LAPIS, N. R. A saúde e os processos de trabalho no capitalismo: reflexões na interface da psicodinâmica do trabalho e da sociologia do trabalho. Revista Psicologia \& Sociedade, Porto Alegre, v. 19, n. 1, p. 61-68, 2007.

MOTTA, F. C. P. Teoria das Organizações: evolução e crítica. São Paulo: Pioneira Thomson Learning, 2003.

MOTTA, P. R. Gestão contemporânea: a ciência e a arte de ser dirigente. 3. ed. Rio de Janeiro: Record, 1993.

MOZZATO, A. R.; GRZYBOVSKI, D. Abordagem crítica nos Estudos Organizacionais: concepção de indivíduo sob a perspectiva emancipatória. Cadernos EBAPE.BR, v. 11, n. 4, p. 503-519, 2013.

NAISBITT, J. Paradoxo global: quanto maior a economia mundial, mais poderosos são os seus protagonistas menores: nações, empresas e indivíduos. 2. ed. Rio de Janeiro: Campus, 1994.

ROHM, R. H. D. A produção de subjetividades em organizações contemporâneas: práticas discursivas e políticas da empregabilidade. 2003. Tese (Doutoramento em Administração) - Escola Brasileira de Administração Pública e de Empresas da Fundação Getulio Vargas, Rio de Janeiro.

SENNETT, R. A Corrosão do caráter: conseqüências pessoais do trabalho no novo capitalismo. Trad. Marcos Santarrita. Rio de Janeiro: Record, 2000.

TOFFLER, A. A terceira onda. 9. ed. Rio de Janeiro: Record, 1987.

TRAGTENBERG, M. Sobre educação, política e sindicalismo. São Paulo: Cortez, 1982.

VIANNA, S. Antecedentes históricos. In: SUSSEKIND, A. et al. Instituições de direito do trabalho. 22. ed. São Paulo: Ltr, 2005. v. 1 e 2.

VIEIRA, E. F.; VIEIRA, M. M. F. A dialética da pós-modernidade: a sociedade em transformação. Rio de Janeiro: Editora FGV, 2004. 